\title{
Application of latent semantic analysis for open- ended responses in a large, epidemiologic study
}

\author{
Travis D Leleu ${ }^{1}$, Isabel G Jacobson ${ }^{*}$, Cynthia A LeardMann ${ }^{1}$, Besa Smith', Peter W Foltz ${ }^{3}$, Paul J Amoroso ${ }^{2}$, \\ Marcia A Derr ${ }^{3}$, Margaret AK Ryan ${ }^{4}$ and Tyler C Smith ${ }^{1}$, for the Millennium Cohort Study Team
}

\begin{abstract}
Background: The Millennium Cohort Study is a longitudinal cohort study designed in the late 1990s to evaluate how military service may affect long-term health. The purpose of this investigation was to examine characteristics of Millennium Cohort Study participants who responded to the open-ended question, and to identify and investigate the most commonly reported areas of concern.
\end{abstract}

Methods: Participants who responded during the 2001-2003 and 2004-2006 questionnaire cycles were included in this study $(n=108,129)$. To perform these analyses, Latent Semantic Analysis (LSA) was applied to a broad openended question asking the participant if there were any additional health concerns. Multivariable logistic regression was performed to examine the adjusted odds of responding to the open-text field, and cluster analysis was executed to understand the major areas of concern for participants providing open-ended responses.

Results: Participants who provided information in the open-ended text field $(n=27,916)$, had significantly lower self-reported general health compared with those who did not provide information in the open-ended text field. The bulk of responses concerned a finite number of topics, most notably illness/injury, exposure, and exercise.

Conclusion: These findings suggest generalized topic areas, as well as identify subgroups who are more likely to provide additional information in their response that may add insight into future epidemiologic and military research.

\section{Background}

Qualitative data can provide epidemiologists with invaluable information that cannot be captured by quantitative data alone. Open-ended survey responses are difficult to analyze quantitatively in a large-scale study due to time constraints and complexity of categorizing the responses in a consistent and unbiased way. Latent Semantic Analysis (LSA) provides a method for open-ended text analysis using sophisticated statistical and mathematical algorithms [1]. This method reveals subtle textual meaning using an automated approach that eliminates potential human bias and permits rapid coding of large amounts of data [2]. LSA is widely used in applications of information retrieval [1], spam filtering [3], and automated essay scoring [4]. To date, modest assessments of LSA's functionality for open-ended text responses have shown promising results [5], opening the field of large-scale

\footnotetext{
* Correspondence: isabel.jacobson@med.navy.mil

'Deployment Health Research Department at Naval Health Research Center,

140 Sylvester Road, San Diego, CA, 92106, USA

Full list of author information is available at the end of the article
}

application of this technique to areas such as epidemiologic survey research.

This investigation explores the use of LSA to analyze open-ended responses from Millennium Cohort Study participants collected from 2001-2006 to investigate important health concerns that may not be covered by the structured questionnaire. Participant responses may also add value to existing research by providing more insight into emerging areas of concern. Additionally, it may prompt suggestions for refining future versions of the questionnaire by including previously omitted topics. The use of LSA for efficient and standardized analysis of open-ended responses from large-scale studies such as the Millennium Cohort will further epidemiological research by allowing researchers to gain deeper insight of populations under study.

\section{Methods}

Population and data sources

This cross-sectional investigation is part of the larger Millennium Cohort Study, which was designed in the late

\section{Biomed Central}

(c) 2011 Leleu et al; licensee BioMed Central Ltd. This is an Open Access article distributed under the terms of the Creative Commons Attribution License (http://creativecommons.org/licenses/by/2.0), which permits unrestricted use, distribution, and reproduction in any medium, provided the original work is properly cited. 
1990s to determine how military service may affect longterm health [6]. Those invited to participate in Panel 1 of the Millennium Cohort Study were randomly selected from all US military personnel, over sampling female service members, Reserve/National Guard service members, and those who had been previously deployed to southwest Asia, Bosnia, or Kosovo from 1998 through 2000, to ensure sufficient power to detect differences in smaller subgroups of the population. The probability-based sample, representing approximately 11.3 percent of the 2.2 million men and women in service as of October 2000, was provided by the Defense Manpower Data Center (DMDC) in California. Of the 77,047 individuals who enrolled (36 percent response rate) from July 2001 to June 2003 in Panel 1, 55,021 (71 percent follow-up rate) completed the first follow-up questionnaire between June 2004 and February 2006. In addition to Panel 1, the invited participants of Panel 2 were randomly selected from military personnel with 1 to 2 years of service as of October 2003, and 31,110 enrolled (25 percent response rate). Marines and women were over sampled in this panel in order to ensure sufficient power among women as well as the most likely group of combat deployers. This investigation began with 108,157 consenting participants who completed a questionnaire from either Panel 1 (baseline and/or follow-up) or Panel 2 baseline. Investigations of nonresponse to the first follow-up questionnaire found no appreciable bias as reflected by comparing measures of association for selected outcomes using complete case and inverse probability weighting [7]. Participants with missing covariate data were removed from analyses. Demographic and military-specific data were obtained from electronic personnel files maintained by DMDC. Variables included sex, birth date, highest education level, marital status, race/ethnicity, past deployment to southwest Asia, Bosnia, or Kosovo between 1998 and 2000, pay grade, service component (active duty and reserve/National Guard), service branch (Army, Navy, Coast Guard, Air Force, and Marine Corps), and occupations.

The questionnaire consisted of 67 questions, including the open-ended question that read, "Do you have any concerns about your health that are not covered in this survey that you would like to share". While other questions allowed for free form text input, they were designed to accommodate only brief responses. The open-ended question was designed for participants to include as much information as they wanted, over any subject they wished to discuss. The huge variance in response topics made simplistic dictionary analysis of the open-ended response untenable. In addition, dictionary based analyses are unable to account for polysemy, a situation where one word can have multiple meanings (e.g., back can mean back pain, backwards, or previous in time).

\section{Latent Semantic Analysis}

LSA is a fully automatic mathematical/statistical technique for extracting and inferring meaningful relations from the contextual usage of words [8,9]. Using LSA software developed by Pearson Knowledge Technologies, lexical analysis was performed on the responses to the final question, which asks participants to share any other health concerns not covered in the structured instrument. This allowed for identifying semantic similarities among open text responses to determine clusters of responses with high contextual similarity (e.g., noting that "welding fumes" and "asbestos" have similar meaning within the context of this study). LSA overcomes the limitations of simple dictionary-based analysis because it determines meaning from contextual similarity, rather than human defined synonyms and related words.

The first step in applying LSA to the analysis of openended responses was to create a semantic space, "a mathematical representation of a large body of text[s]" [9], using a corpus of medical and military documents as well as the text of the questionnaire itself and the open-ended responses. The semantic space was generated from 1,862,972 medical and military documents comprising 435,456 unique terms. These documents included medical journal articles containing health related writings, military documents replete with jargon and geographical locations, plus common English language works. In addition, the open-ended responses were included in the semantic space in order to identify semantic similarities that would not exist outside the context of an openended response. To reduce complexity, the size of the semantic space was optimized by LSA to have $n=300$ dimensions. Data were then filtered by removing responses that conveyed no information about the health of the participant (e.g., "No," "N/A," "I have nothing to say"). This removed entire responses from the analysis, an important distinction from the common tactic of employing a "stop list", which removes common words (e.g., "and", "the", etc.) from specific responses. In this analysis, every word in every response was considered for analysis; only the responses determined to convey no meaning were removed. Once identified, those individuals with meaningless responses $(n=33,951)$ were included in the group of participants who did not respond to the open-ended question. Upon human examination, 25 (0.1 percent) responses were originally classified as meaningless that were subsequently reclassified as meaningful. To investigate the number of responses misclassified as meaningful, a random sample of 250 responses originally classified as meaningful were reviewed by humans. Of these, only 5 ( 2.0 percent) were judged to be actual meaningless responses. Therefore, the classification method biased slightly toward categorizing responses as meaningful rather than the opposite. 
Implications of this small amount of misclassification are expected to have minimal effects on our study findings.

A set of 1025 clustering terms was created by selecting words from the meaningful responses that each appeared more than 70 times (excluding words in a high-frequency stop list; a stop list was not used in the creation of the semantic space). LSA was used to compute a dissimilarity measure by computing the cosine between each pair of terms in the set to produce a distance matrix. The set of terms was partitioned into 20 non-overlapping clusters using a variant of the k-means clustering algorithm, called the pam (for "partitioning around medoids") function from the R language cluster package. Twenty clusters were chosen since more than 20 clusters gave redundant or overlapping clusters, or clusters that were not relevant to the medical domain (e.g. measures of time, military terms). Fewer than 20 clusters did not provide sufficient separation into separate categories. Each cluster was represented by its medoid, the term most central in the cluster. Meaningful responses were assigned to clusters by computing the similarity between each response and each cluster medoid. If the cosine between a response and a medoid (representing the vector distance between a given response and the cluster medoid) was greater than 0.2 , the response was assigned to that cluster. The clusters were then ranked based on how many responses they contained. The 20 clusters that accounted for the most responses were examined to determine their semantic meaning. However, not all of the top-20 clusters had discernable semantic meaning; some clusters appeared to be an artifact of the LSA technology (e.g., the cluster described by the following terms: a lot, don't, haven't, isn't, believed). For this exploratory analysis, the clusters without obvious semantic meaning were not included due to the difficulty determining the topic of concern. Responses could be assigned to multiple clusters, though this occurred infrequently. This analysis resulted in 24,181 (86.6 percent) of the 27,916 meaningful responses being assigned to at least one area of concern (represented by membership in a cluster).

\section{Statistical analysis}

Descriptive and quantitative analyses of demographic characteristics among those who did and did not respond to the open-ended question were performed. Multivariable logistic regression modeling was used to investigate associations between demographic characteristics and whether they responded to the open-ended text question. A separate logistic regression model was run for Panel 1 baseline, Panel 1 follow-up, and Panel 2 baseline populations. All statistical data analyses were performed using SAS statistical software version 9.2 (SAS Institute Inc., Cary, NC).

\section{Results}

The semantic space was generated from $1,862,972$ medical and military documents comprising 435,456 unique terms using 300 dimensions. Of the 108,157 eligible participants, 19 were removed due to missing information for education and marital status, leaving 108,138 participants for analyses. Of the 108,138 participants in the study who completed 163,159 surveys from 2001-2006 (encompassing Panel 1 baseline and follow-up, and Panel 2 baseline), 61,507 surveys (37.7 percent) had a response in the openended field. There were 670 unique null patterns (indicating a meaningless response) identified, resulting in 33,591 of the open-ended responses ( 54.6 percent) being classified as having a meaningless response. Subsequently, 27,916 (45.4 percent of open-ended responses, 17.1 percent of all completed surveys) were classified with meaningful responses.

Table 1 describes characteristics of Millennium Cohort Study participants who responded to the open-ended question, stratified by panel and survey. Open-ended responders were generally representative of their overall panel characteristics. However, for all three groups, a higher proportion of open-ended responders were older, on active duty, Army members, and combat specialists. Education level did not have a significant effect on response to the open ended question. In addition, openended responders were more likely to self-report good, fair, or poor general heath compared with those who did not provide an open-ended response who were more likely to report very good or excellent health.

The adjusted odds of response to the open-ended question for each of the respective response groups are displayed in Table 2. Increased adjusted odds of response to the open-ended question were found in personnel with service in the Army, Navy/Coast Guard, and the Marine Corps in comparison with Air Force members. Cohort members who were older, serving on active duty and in combat specialties were significantly more likely to respond to the open-ended question across all panels. Black non-Hispanic participants were significantly less likely to respond than white non-Hispanic participants. Among all panels, those who indicated fair or poor health were nearly three times more likely to respond when compared with those reporting very good or excellent health. Panel 1 women were more likely than men to provide a meaningful open-ended response, while no sex difference was observed among Panel 2 participants. Panel 1 baseline participants with deployment experience between 2001 and 2007 in support of the operations in Iraq and Afghanistan were less likely to respond to the open-ended question. However, Panel 1 follow-up and Panel 2 baseline participants with deployment experience in support of the operations in Iraq and Afghanistan were more likely to respond to the open-ended question. 
Table 1 Characteristics of Millennium Cohort Study Participants Who Provided a Meaningful Response for the Open-Ended Question

\begin{tabular}{|c|c|c|c|c|c|c|}
\hline \multirow[b]{2}{*}{ Characteristic } & \multicolumn{2}{|c|}{ Panel 1 Baseline } & \multicolumn{2}{|c|}{ Panel 1 Follow-up } & \multicolumn{2}{|c|}{ Panel 2 Baseline } \\
\hline & $\begin{array}{c}\text { All responders } \\
n=77,042\end{array}$ & $\begin{array}{c}\text { Open-text responders }^{\mathrm{a}} \\
n=14,692\end{array}$ & $\begin{array}{c}\text { All responders } \\
n=55,021\end{array}$ & $\begin{array}{c}\text { Open-text responders }^{\mathrm{a}} \\
n=8,937\end{array}$ & $\begin{array}{c}\text { All responders } \\
n=31,096\end{array}$ & $\begin{array}{c}\text { Open-text responders }^{\mathrm{a}} \\
n=4,287\end{array}$ \\
\hline & $\%^{\mathrm{b}}$ & $\%^{\mathbf{b}}$ & $\%^{\mathrm{b}}$ & $\%^{\mathbf{b}}$ & $\%^{\mathrm{b}}$ & $\%^{\mathbf{b}}$ \\
\hline \multicolumn{7}{|l|}{ Sex } \\
\hline Male & 73.2 & 73.2 & 73.3 & 72.8 & 61.6 & 63.4 \\
\hline Female & 26.8 & 26.8 & 26.7 & 27.2 & 38.4 & 36.6 \\
\hline \multicolumn{7}{|l|}{ Birth year } \\
\hline Before 1960 & 21.6 & 24.2 & 24.5 & 28.1 & 0.7 & 0.9 \\
\hline 1960-1969 & 37.9 & 39.2 & 40.5 & 40.5 & 5.4 & 6.3 \\
\hline 1970-1979 & 34.6 & 31.8 & 30.8 & 28.1 & 31.9 & 35.6 \\
\hline 1980 or later & 5.9 & 4.7 & 4.2 & 3.3 & 62.0 & 57.2 \\
\hline \multicolumn{7}{|l|}{ Education } \\
\hline High school or less & 48.9 & 48.9 & 45.6 & 43.3 & 81.4 & 80.6 \\
\hline Some college & 25.5 & 24.3 & 17.8 & 18.4 & 3.2 & 4.0 \\
\hline Bachelor's degree & 16.5 & 16.7 & 22.1 & 22.7 & 12.3 & 12.7 \\
\hline Advanced degree & 9.1 & 10.1 & 14.5 & 15.6 & 3.1 & 2.7 \\
\hline \multicolumn{7}{|l|}{ Marital status } \\
\hline Married & 63.1 & 64.1 & 73.3 & 72.8 & 28.1 & 29.0 \\
\hline Not married & 36.9 & 35.9 & 26.7 & 27.2 & 71.9 & 71.0 \\
\hline \multicolumn{7}{|l|}{ Race/ethnicity } \\
\hline White non-Hispanic & 69.6 & 70.6 & 70.8 & 69.9 & 71.2 & 72.2 \\
\hline Black non-Hispanic & 13.8 & 11.6 & 12.2 & 11.0 & 11.6 & 10.2 \\
\hline Other & 16.7 & 17.8 & 16.9 & 19.1 & 17.1 & 17.6 \\
\hline \multicolumn{7}{|l|}{ 2001-2007 deployment ${ }^{c}$} \\
\hline No & 57.6 & 61.4 & 56.3 & 56.1 & 42.3 & 38.4 \\
\hline Yes & 42.5 & 38.6 & 43.6 & 43.9 & 57.7 & 61.6 \\
\hline \multicolumn{7}{|l|}{ Military rank } \\
\hline Enlisted & 77.0 & 75.7 & 70.8 & 69.4 & 88.4 & 89.4 \\
\hline Officer & 23.0 & 24.3 & 29.2 & 30.6 & 11.6 & 10.6 \\
\hline \multicolumn{7}{|l|}{ Service component } \\
\hline Reserve/Guard & 43.0 & 36.8 & 53.4 & 51.3 & 40.0 & 36.7 \\
\hline Active duty & 57.0 & 63.2 & 46.6 & 48.7 & 60.0 & 63.3 \\
\hline \multicolumn{7}{|l|}{ Branch of service } \\
\hline Air Force & 29.0 & 25.7 & 30.3 & 24.7 & 26.6 & 17.9 \\
\hline Army & 47.4 & 48.1 & 47.7 & 52.1 & 48.2 & 55.0 \\
\hline Navy/Coast Guard & 18.5 & 20.6 & 18.1 & 18.8 & 16.9 & 16.8 \\
\hline Marine Corps & 5.1 & 5.6 & 4.0 & 4.3 & 8.3 & 10.3 \\
\hline
\end{tabular}


Table 1 Characteristics of Millennium Cohort Study Participants Who Provided a Meaningful Response for the Open-Ended Question (Continued)

\begin{tabular}{|c|c|c|c|c|c|c|}
\hline Others & 69.9 & 69.0 & 69.4 & 68.3 & 72.5 & 72.0 \\
\hline Combat specialists & 20.0 & 21.2 & 19.2 & 20.3 & 15.7 & 19.1 \\
\hline Heath care specialists & 10.4 & 9.8 & 11.4 & 11.4 & 11.8 & 8.9 \\
\hline \multicolumn{7}{|l|}{ General health $^{d}$} \\
\hline Very good/excellent & 59.0 & 48.9 & 55.3 & 45.6 & 54.3 & 41.4 \\
\hline Good & 30.3 & 35.1 & 34.5 & 37.4 & 33.1 & 37.8 \\
\hline Fair/poor & 7.7 & 13.3 & 8.9 & 15.9 & 8.9 & 17.7 \\
\hline Missing & 3.0 & 2.7 & 1.3 & 1.0 & 3.6 & 3.1 \\
\hline
\end{tabular}

Includes participants who had a meaningful response to the open-ended question, "Do you have any concerns that are not covered in this survey that you would like to share?"

${ }^{b}$ Percentages were rounded and may not sum to 100 .

c Any deployment in support of the wars in Iraq and Afghanistan September 2001-October 2007.

'Self-reported general health from the question, "In general, would you say your health is excellent, very good, good, fair, or poor?" 
Table 2 Adjusted Odds of Response to the Open-Ended Question by Characteristics of Millennium Cohort Study Participants

\begin{tabular}{|c|c|c|c|c|c|c|}
\hline \multirow[b]{3}{*}{ Characteristic } & \multicolumn{6}{|c|}{ Adjusted Odds of Response to Open-Ended Question ${ }^{a}$} \\
\hline & \multicolumn{2}{|c|}{$\begin{array}{l}\text { Panel } 1 \text { Baseline } \\
n=74,664\end{array}$} & \multicolumn{2}{|c|}{$\begin{array}{c}\text { Panel } 1 \text { Follow-up } \\
n=54,250\end{array}$} & \multicolumn{2}{|c|}{$\begin{array}{l}\text { Panel } 2 \text { Baseline } \\
n=29,902\end{array}$} \\
\hline & AOR & $95 \% \mathrm{Cl}$ & AOR & $95 \% \mathrm{Cl}$ & AOR & $95 \% \mathrm{Cl}$ \\
\hline \multicolumn{7}{|l|}{ Sex } \\
\hline Male & ref & & ref & & ref & \\
\hline Female & $1.07^{*}$ & $1.02,1.12$ & $1.09^{*}$ & $1.03,1.16$ & 1.00 & $0.92,1.07$ \\
\hline \multicolumn{7}{|l|}{ Birth year } \\
\hline Before 1960 & 1.00 & & 1.00 & & 1.00 & \\
\hline 1960-1969 & $0.83^{*}$ & $0.79,0.87$ & $0.81^{*}$ & $0.76,0.86$ & 0.78 & $0.53,1.15$ \\
\hline 1970-1979 & $0.65^{*}$ & $0.61,0.96$ & $0.71^{*}$ & $0.67,0.76$ & $0.64^{*}$ & $0.44,0.93$ \\
\hline 1980 or later & $0.52^{*}$ & $0.47,0.58$ & $0.57^{*}$ & $0.50,0.65$ & $0.49^{*}$ & $0.34,0.71$ \\
\hline \multicolumn{7}{|l|}{ Education } \\
\hline High school or less & ref & & ref & & ref & \\
\hline Some college & 1.03 & $0.98,1.09$ & $1.09^{*}$ & $1.02,1.16$ & $1.33^{*}$ & $1.11,1.59$ \\
\hline Bachelor's degree & 1.07 & $0.99,1.15$ & $1.13^{*}$ & $1.05,1.22$ & $1.17^{*}$ & $1.00,1.37$ \\
\hline Advanced degree & 1.07 & $0.97,1.18$ & $1.17^{*}$ & $1.06,1.29$ & 1.15 & $0.88,1.50$ \\
\hline \multicolumn{7}{|l|}{ Marital status } \\
\hline Married & ref & & ref & & ref & \\
\hline Not married & $1.09^{*}$ & $1.04,1.14$ & $1.06^{*}$ & $1.01,1.12$ & 1.06 & $0.98,1.14$ \\
\hline \multicolumn{7}{|l|}{ Race/ethnicity } \\
\hline White non-Hispanic & ref & & ref & & ref & \\
\hline Black non-Hispanic & $0.71^{*}$ & $0.67,0.75$ & $0.82^{*}$ & $0.76,0.88$ & $0.80^{*}$ & $0.72,0.90$ \\
\hline Other & $0.95^{*}$ & $0.90,1.00$ & $1.07^{*}$ & $1.00,1.14$ & 0.99 & $0.90,1.08$ \\
\hline \multicolumn{7}{|l|}{ 2001-2007 deployment ${ }^{\text {b }}$} \\
\hline No & ref & & ref & & ref & \\
\hline Yes & $0.88^{*}$ & $0.84,0.91$ & $1.13^{*}$ & $1.08,1.19$ & $1.10^{*}$ & $1.02,1.18$ \\
\hline \multicolumn{7}{|l|}{ Military rank } \\
\hline Enlisted & ref & & ref & & ref & \\
\hline Officer & 1.07 & $0.99,1.15$ & 1.05 & $0.97,1.14$ & 1.06 & $0.88,1.27$ \\
\hline \multicolumn{7}{|l|}{ Service component } \\
\hline Reserve/Guard & ref & & ref & & ref & \\
\hline Active duty & $1.50^{*}$ & $1.44,1.57$ & $1.14^{*}$ & $1.09,1.20$ & $1.32^{*}$ & $1.22,1.43$ \\
\hline \multicolumn{7}{|l|}{ Branch of service } \\
\hline Air Force & ref & & ref & & ref & \\
\hline Army & $1.30^{*}$ & $1.24,1.38$ & $1.43^{*}$ & $1.35,1.52$ & $1.72^{*}$ & $1.57,1.88$ \\
\hline Navy/Coast Guard & $1.26^{*}$ & $1.18,1.34$ & $1.35^{*}$ & $1.26,1.45$ & $1.39^{*}$ & $1.24,1.55$ \\
\hline Marine Corps & $1.42^{*}$ & $1.30,1.56$ & $1.56^{*}$ & $1.38,1.76$ & $1.82^{*}$ & $1.59,2.08$ \\
\hline \multicolumn{7}{|l|}{ Occupational category } \\
\hline Others & ref & & ref & & ref & \\
\hline Health care specialists & $0.90^{*}$ & $0.84,0.96$ & 1.00 & $0.93,1.08$ & $0.76^{*}$ & $0.67,0.86$ \\
\hline Combat specialists & $1.07^{*}$ & $1.02,1.13$ & $1.08^{*}$ & $1.02,1.15$ & $1.18^{*}$ & $1.07,1.29$ \\
\hline \multicolumn{7}{|l|}{ General health $^{c}$} \\
\hline Very good/excellent & ref & & ref & & ref & \\
\hline Good & $1.55^{*}$ & $1.49,1.61$ & $1.47^{*}$ & $1.39,1.54$ & $1.60^{*}$ & $1.48,1.72$ \\
\hline Fair/poor & $2.66^{*}$ & $2.50,2.84$ & $2.79^{*}$ & $2.59,3.00$ & $3.08^{*}$ & $2.79,3.41$ \\
\hline
\end{tabular}

*Indicates statistical significance at the $\alpha=0.05$ level, with a 95\% confidence interval that excluded 1.00 .

a Includes participants who had a meaningful response to the open-ended question, "Do you have any concerns that are not covered in this survey that you would like to share? A separated logistic regression model was run for panel 1 baseline, panel 1 follow-up, and panel 2 baseline populations.

${ }^{\mathrm{b}}$ Any deployment in support of the wars in Iraq and Afghanistan September 2001-October 2007.

" Self-reported general health from the question, "In general, would you say your health is excellent, very good, good, fair, or poor?" 
Table 3 shows some example responses, as well as their associated clusters. Each row represents one cluster, with an example participant response displayed. Although the illness/injury cluster includes both chronic and acute concerns, blood pressure medication was the most commonly expressed issue. Exposure concerns were mostly either workplace hazards (e.g. toxic chemicals) or deployment concerns (e.g., being around strange chemicals during deployment). The responses classified in the exercise cluster mainly focused on fitness, although some responses overlapped between exercise and injury. Mental health included a wide range of responses, from childhood abuse to concerns about postdeployment readjustment. Although not readily apparent using human analysis, anxiety was identified as a separate cluster from mental health using LSA. Vaccination concerns were frequently expressed, even though the structured questionnaire contained a few vaccine questions.

The most frequently expressed areas of concern are shown in Table 4. Responders to the open-ended question most frequently expressed a concern with an illness or injury (28.0 percent). Terms present in the response that represented illness or injury concerns included words such as "suffered," "recovered," and "developed." Some of the other more frequently expressed areas of concern were exposure, discussed in 13.6 percent of open-ended responses and indicated by words such as "chemicals," "radiation," and "asbestos"; and exercise, discussed in 11.0 percent of open-ended responses, represented by terms such as "walking," "biking," and "vigorous". Other common concerns were back pain (8.8 percent), deployment (7.6 percent), arm symptoms (7.4 percent), mental health (7.2 percent), weight (6.3 percent), vaccination ( 4.5 percent), anxiety/disorientation (3.5 percent), and surgery (2.1 percent). Panel 1 open-ended responders more frequently expressed concerns about deployment at follow-up (8.3 percent) compared with baseline (7.1 percent). Compared with the total study population, a greater proportion of Panel 1 follow-up and Panel 2 baseline responders, who both filled out their respective survey from 2004-2006, indicated concerns about deployment and mental health.

\section{Discussion}

As computing capabilities grow, researchers are increasingly given opportunities to use complex and computationally intensive analytic techniques to answer scientific questions. Confronted with practical challenges of analyzing open-text responses, LSA offers a comprehensive method for efficient and standardized analysis of these data. In this exploratory analysis, we found subgroups of the population that were more likely to use the open-text response option. Of greatest interest are those who reported poor general health and their propensity to use the open-text field. Since these individuals may be of high concern in health research, this text field yields additional valuable insight not otherwise assessed.

Limited research exists on the characteristics of individuals who choose to provide additional information as part of an optional open-ended text field on a survey. The strongest association observed in this study was that participants with poorer self-reported general health were significantly more likely to respond within the open-ended text field, and the likelihood of response increased as selfreported health status decreased. Interestingly, in the entire Millennium Cohort, it has been shown that there is not a significant association between health status and likelihood of enrollment [10]. However, it is important to note that all of the individuals in this current study were already participants in the Millennium Cohort Study; therefore, even though they may not have enrolled based on their health status, perhaps health status motivated them to provide additional information in the open-ended field. Those with poor self-perceived general health may

Table 3 Example Responses From Millennium Cohort Study Participants Within the Top Seven Concerns Expressed in the Open-Ended Question

\begin{tabular}{|c|c|}
\hline Area of Concern ${ }^{a}$ & Example Response \\
\hline Illness/injury & I recently had my blood pressure medication dose increased to control hypertension \\
\hline Illness/injury & $\begin{array}{l}\text { I was involved in a motor vehicle collision...It has caused delays in my return to reserve duty/flight duty. I suffered a head } \\
\text { injury/laceration and orthopedic injury/laceration to left knee. }\end{array}$ \\
\hline \multirow[t]{2}{*}{ Exposure } & Exposed to hepatitis, asbestos, and enriched uranium in Uzbekistan and Afghanistan. \\
\hline & Exposure to welding fumes. \\
\hline Exercise & Lower back, knee, and ankle pain due to extended periods of massive weight-bearing duties and exercise. \\
\hline Mental health & Mental and emotional problems due to sexual child abuse. \\
\hline $\begin{array}{l}\text { Anxiety/ } \\
\text { disorientation }\end{array}$ & Extreme stress and anxiety due to superiors' incompetence. \\
\hline Vaccination & Allergic reactions to anthrax vaccine. \\
\hline
\end{tabular}

${ }^{a}$ A single participant response could be categorized into multiple areas of concern.

'The cluster labeled "illness/injury" describes responses across a broad number of concerns. Several examples are provided in Table 4 to better illustrate these topic areas within the cluster. 
Table 4 Most Frequently Expressed Areas of Concern Among Millennium Cohort Study Participants Responding to the Open-Ended Text Question

\begin{tabular}{|c|c|c|c|c|c|c|c|c|c|}
\hline \multirow[t]{2}{*}{ Area of Concern ${ }^{a}$} & \multicolumn{2}{|c|}{$\begin{array}{c}\text { Total } \\
n=10,214\end{array}$} & \multicolumn{2}{|c|}{$\begin{array}{c}\text { P1 Baseline Responses } \\
n=5,626\end{array}$} & \multicolumn{2}{|c|}{$\begin{array}{l}\text { P1 Follow-up Responses } \\
n=3,297\end{array}$} & \multicolumn{2}{|c|}{$\begin{array}{l}\text { P2 Baseline Responses } \\
n=1,291\end{array}$} & \multirow[t]{2}{*}{ Related Terms ${ }^{b}$} \\
\hline & $n$ & $\%$ & $n$ & $\%$ & $n$ & $\%$ & $n$ & $\%$ & \\
\hline Illness/injury & 2,859 & 28.0 & 1,433 & 25.5 & 1,033 & 31.3 & 393 & 30.4 & suffered, recovered, developed \\
\hline Exposure & 1,385 & 13.6 & 887 & 15.8 & 328 & 10.0 & 170 & 13.2 & chemicals, radiation, asbestos \\
\hline Exercise & 1,125 & 11.0 & 613 & 10.9 & 391 & 11.9 & 121 & 9.4 & walking, biking, vigorous \\
\hline Back pain & 903 & 8.8 & 482 & 8.6 & 313 & 9.5 & 108 & 8.4 & discs, herniation, lumbar \\
\hline Deployment regions/concerns & 780 & 7.6 & 399 & 7.1 & 275 & 8.3 & 106 & 8.2 & Bosnia, barracks, DU \\
\hline Arm & 754 & 7.4 & 465 & 8.3 & 225 & 6.8 & 64 & 5.0 & elbow, pronate, grip \\
\hline Mental health & 735 & 7.2 & 385 & 6.8 & 240 & 7.3 & 110 & 8.5 & emotional, interpersonal, anxiety \\
\hline Weight concerns & 647 & 6.3 & 354 & 6.3 & 206 & 6.3 & 87 & 6.7 & lose, dieting, obesity \\
\hline Vaccination & 459 & 4.5 & 299 & 5.3 & 114 & 3.5 & 46 & 3.6 & VAERS, influenza, boosters \\
\hline Anxiety/disorientation & 355 & 3.5 & 185 & 3.3 & 117 & 3.6 & 53 & 4.1 & shortness, sweating, tiredness \\
\hline Surgery & 212 & 2.1 & 124 & 2.2 & 55 & 1.7 & 33 & 2.6 & removed, tape, wrapped \\
\hline
\end{tabular}

Participants were able to provide a response in more than one area at multiple time points

${ }^{b}$ Example terms included in the same cluster that is described by the Area of Concern 
be more likely to report symptoms [11], or perhaps they have a desire to explain their poor health in greater detail than do healthier individuals. Regardless of why individuals with poorer self-reported general health are more likely to respond to the open-ended question, this finding should be considered when conducting future analyses of response bias in the Millennium Cohort.

With nearly 1 in 5 respondents choosing to include information in the open text field, it is important to know their characteristics. Adjusted data interestingly suggest some weak patterns, albeit significant, in response to the open text field differentiated by sex, age, active-duty status, and combat occupations. Air Force personnel were least likely to include a meaningful response to the question, but were also most likely to respond and respond early to the initial invitation for enrollment $[6,12]$. Combat specialists and Marine Corps members were also more likely to respond to the open text question, which may be attributable to the ongoing combat operations in Iraq and Afghanistan. Other findings of education status indicate that response rates generally increase as education level increases; this does not hold true for the open ended response. This non effect could be attributed to the free form nature of the open-ended text field; reading comprehension of the participant may be less of an issue when compared with the structured instrument.

Another interesting finding is that illness/injury was by far the most frequently expressed area of concern. This may suggest that physical or emotional ailments cause concern for people; either about how or why illness or injury occurred, or how these ailments may affect their short- or long-term quality of life. It is also worth noting that a higher proportion of individuals reported concerns regarding either illness/injury or deployment on the 2004-2006 assessment compared with the 2001-2003 assessment. This may be a reflection of the increased deployments to Iraq and Afghanistan as the conflicts continued to heighten over this time period. With only one follow-up data point available for the present study, it was difficult to fully understand this relationship; however, it will be interesting to examine whether these concerns persist at the same or increased levels in the 20072008 and future assessments.

The Millennium Cohort Study team re-examines the structured survey instrument between survey cycles, frequently adding questions that were not originally included in the previous instrument. Based in part on the open-ended text analysis described in this paper, several changes have been made: in 2004, physical activity questions were added to the survey; in 2007 questions were added that focused on physical injury and deploymentspecific exposures; in 2010, the physical injury section was supplemented, and questions on sleep length and quality were included. There was a very small proportion of responses related to very specific chemical exposures or other topics that were outside the scope of the survey, or very specific to a few individuals. The open ended question allows a channel for participants to raise awareness of newly identified, cutting edge topics that can help inform survey designers.

There are some limitations to these analyses that should be mentioned. The study population consisted of a sample of responders to the Millennium Cohort questionnaire and may not be representative of the military population. However, investigations of potential biases in the Millennium Cohort have found a well-representative military cohort who report reliable data and who are not influenced to participate by poor health prior to enrollment [6,10,13-20]. Latent Semantic Analysis is a technique to transform qualitative data into quantitative information, but it has limitations, including situations where meaning is determined contextually. Additionally, it is possible that non obvious underlying relationships existed within the top-20 automatically generated clusters, which could reveal more concerns that we were unable to detect. While these clusters were not included in the attached tables, they were included in the demographic analysis. The greatest limitation to using LSA on open-ended text responses, however, is the vagueness in grouping certain responses together. LSA approximates semantic meaning (related concerns) by using mathematical transformations as a proxy; not all mathematically related responses were obviously similar. This made it more difficult to cleanly distinguish between different clusters when performing the final analysis.

Despite these limitations, there are important strengths of this analysis. To our knowledge, this study is one of the first to apply LSA-based analyses to open-ended epidemiologic survey responses from a large US military population. This is also one of the first studies to examine the openended text responses from US military personnel, including reserve/National Guard, and members who have left military service. Previous analyses on military populations used human assisted computer analysis, but generally had less sophisticated methodologies [21]. Once the initial semantic space is created, LSA is fully automatic, permitting rapid analysis of large sets of responses. Because knowledge of word meaning is not derived from thesauri, ontologies, or hand-coding of relationships among words or among responses, bias from human coders and interpretation error is minimized. LSA can evaluate a word whose meaning is determined contextually (e.g., "we moved back," is differentiated from "hurt my back"). Furthermore, it can determine similarity among responses without accounting for word order or even if passages share no words in common [22]. We also examined the reliability of LSA versus human expert review of a random sample of 50 open-ended responses using the Kappa 
coefficient [23], and found agreement between LSA and human review to be substantial to almost perfect for four out of five categories examined, bolstering confidence in the LSA technology.

\section{Conclusion}

Future directions of this work may include application of analyses to better define concerns within the Cohort. Comparisons between the structured response and openended sections could be used to evaluate the comprehension of the structured instrument. Open-ended text can reveal additional issues of prominent importance to participants. Investigators are continually challenged with addressing symptom-based illness that may not be welldefined under previous disease paradigms, and openended responses among large populations are critical to understanding such complex syndromes [24]. In addition, as society increasingly prefers brief, text-based communication for many health issues, analyses of written messages among populations may reveal important public health trends [25]. Computerized text-parsing tools such as LSA allow an objective review of text responses that would be otherwise impossible to standardize. LSA may be used to define health concerns with related context, and identify whether they represent large-scale concerns of a few individuals or common concerns of a great many individuals. Results will continue to help drive directions of future research and survey content. Review of open-ended text with text-mining tools such as LSA is critical to allow participant voices to truly be heard, from within the bounds of large-scale epidemiologic survey studies.

\footnotetext{
Acknowledgements

This research represents Naval Health Research Center report 10-08, supported by the Department of Defense, under work unit no. 60002 and has been conducted in compliance with all applicable federal regulations governing the protection of human subjects in research (Protocol NHRC.2000.0007). Financial support: The Millennium Cohort Study is funded through the Military Operational Medicine Research Program of the US Army Medical Research and Materiel Command, Fort Detrick, Maryland. The funding organization had no role in the design and conduct of the study; collection, analysis, or preparation of data; or preparation, review, or approval of the manuscript.

The authors would like to thank Scott L. Seggerman from the Management Information Division, US Defense Manpower Data Center, Monterey, CA; Michelle LeWark from the Naval Health Research Center; and all the professionals from the US Army Medical Research and Materiel Command, especially those from the Military Operational Medicine Research Program, Fort Detrick, MD. We appreciate the support of the Henry M. Jackson Foundation for the Advancement of Military Medicine, Rockville, MD. In addition to the authors, the Millennium Cohort Study team includes Melissa Bagnell, Gia Gumbs, Nisara Granado, Dennis Hernando, Jamie Horton, Kelly Jones, Lauren Kipp, William Lee, Amanda Pietrucha, Teresa Powell, Amber Seelig, Katherine Snell, Steven Speigle, Kari Sausedo, Beverly Sheppard, Martin White, James Whitmer, and Charlene Wong, from the Deployment Health Research Department, Naval Health Research Center, San Diego, CA; Edward J Boyko, from the Seattle Epidemiologic Research and Information Center, Veterans Affairs Puget Sound Health Care System, Seattle, WA; Gary D. Gackstetter, from the Department of Preventive Medicine and Biometrics, Uniformed Services University of the Health
}

Sciences, Bethesda, MD, and Analytic Services Inc. (ANSER), Arlington, VA; Gregory C. Gray, from the College of Public Health and Health Professions, University of Florida, Gainesville, FL; Tomoko I. Hooper, from the Department of Preventive Medicine and Biometrics, Uniformed Services University of the Health Sciences, Bethesda, MD; James R. Riddle; and Timothy S. Wells from the Naval Health Research Center, San Diego, CA.

Disclaimer: The views expressed in this article are those of the authors and do not reflect the official policy or position of the Department of the Navy, Department of the Army, Department of the Air Force, Department of Defense, Department of Veterans Affairs, or the US Government.

\section{Author details}

'Deployment Health Research Department at Naval Health Research Center, 140 Sylvester Road, San Diego, CA, 92106, USA. ²MultiCare Research Institute, Tacoma, WA, 98415, USA. ${ }^{3}$ Pearson Knowledge Technologies, 4940 Pearl East Circle, Suite 200, Boulder, CO, 80301, USA. ${ }^{4}$ Naval Hospital Camp Pendleton, Box 555191, Camp Pendleton, CA, 92055, USA.

\section{Authors' contributions}

All authors worked together on the conception, design, and methodology of the study. PF and MD performed the Latent Semantic Analysis and computerized text processing. IJ and CL performed the statistical analyses. $T L, I J, C L, B S, P A, M R$, and TS participated in the interpretation of the analyses. TL, IJ, CL, BS, PF, MD, MR, and TS all participated in the authorship of the manuscript. All authors read and approved the final manuscript.

\section{Competing interests}

The authors declare that they have no competing interests.

Received: 10 January 2011 Accepted: 5 October 2011

Published: 5 October 2011

\section{References}

1. Papadimitriou CH, Tamaki H, Raghavan P, Vempala S: Latent semantic indexing: a probabilistic analysis. Proceedings of the seventeenth ACM SIGACT-SIGMOD-SIGART symposium on Principles of database systems 1998, 159-168.

2. Landauer TK, Dumais ST: How come you know so much? From practical problem to new memory theory. In Basic and applied memory research: Theory in context. Edited by: Hermann D, McEvoy C, Hertzog C, Hertel P, Johnson M. Mahwah, NJ: Erlbaum; 1996:105-126.

3. Sun J, Zhang Q, Yuan Z, Huang W, Yan X, Dong J: Research of Spam Filtering System Based on LSA and SHA. Proceedings of the 5th international symposium on Neural Networks: Advances in Neural Networks Beijing, China: Springer-Verlag; 2008, 331-340.

4. Landauer TK, Dumais ST: A solution to Plato's problem: The Latent Semantic Analysis theory of the acquisition, induction, and representation of knowledge. Psychol Rev 1997, 104:211-240.

5. Foltz PW: Latent Semantic Analysis for text-based research. Behav Res Methods Instrum Comput 1996, 28(2):197-202.

6. Ryan MA, Smith TC, Smith B, Amoroso P, Boyko EJ, Gray GC, et al: Millennium Cohort: enrollment begins a 21-year contribution to understanding the impact of military service. J Clin Epidemiol 2007, 60(2):181-91.

7. Littman AJ, Boyko EJ, Jacobson IG, Horton J, Gackstetter GD, Smith B, et al: Assessing nonresponse bias at follow-up in a large prospective cohort of relatively young and mobile military service members. BMC Med Res Methodol 2010, 10(1):99.

8. Deerwester S, Dumais ST, Landauer TK, Furnas GW, Harshman RA: Indexing by Latent Semantic Analysis. J Am Soc Inf Sci Technol 1990, 41(6):391-407.

9. Landauer TK, Foltz PW, Laham D: Introduction to Latent Semantic Analysis. Discourse Process 1998, 25:259-284.

10. Wells TS, Jacobson IG, Smith TC, Spooner CN, Smith B, Reed RJ, et al: Prior health care utilization as a potential determinant of enrollment in a 21year prospective study, the Millennium Cohort Study. Eur J Epidemiol 2008, 23(2):79-87.

11. Blazer DGl, Houpt JL: Perception of poor health in the healthy older adult. J Am Geriatr Soc 1979, 27(7):330-4.

12. Chretien JP, Chu LK, Smith TC, Smith B, Ryan MA: Demographic and occupational predictors of early response to a mailed invitation to enroll in a longitudinal health study. BMC Med Res Methodol 2007, 7:6. 
13. Riddle JR, Smith TC, Smith B, Corbeil TE, Engel CC, Wells TS, et al: Millennium Cohort: the 2001-2003 baseline prevalence of mental disorders in the U.S. military. J Clin Epidemiol 2007, 60(2):192-201.

14. Smith B, Leard CA, Smith TC, Reed RJ, Ryan MA: Anthrax vaccination in the Millennium Cohort: validation and measures of health. Am J Prev Med 2007, 32(4):347-53.

15. Smith B, Smith TC, Gray GC, Ryan MA: When epidemiology meets the Internet: Web-based surveys in the Millennium Cohort Study. Am J Epidemiol 2007, 166(11):1345-54.

16. Smith B, Wingard DL, Ryan MA, Macera CA, Patterson TL, Slymen DJ: U.S. military deployment during 2001-2006: comparison of subjective and objective data sources in a large prospective health study. Ann Epidemiol 2007, 17(12):976-82.

17. Smith TC, Jacobson IG, Smith B, Hooper TI, Ryan MA: The occupational role of women in military service: validation of occupation and prevalence of exposures in the Millennium Cohort Study. Int J Environ Health Res 2007, 17(4):271-84

18. Smith TC, Smith B, Jacobson IG, Corbeil TE, Ryan MA: Reliability of standard health assessment instruments in a large, population-based cohort study. Ann Epidemiol 2007, 17(7):525-32.

19. Smith TC, Zamorski M, Smith B, Riddle JR, Leardmann CA, Wells TS, et al: The physical and mental health of a large military cohort: baseline functional health status of the Millennium Cohort. BMC Public Health $2007,7: 340$

20. LeardMann CA, Smith B, Smith TC, Wells TS, Ryan MA: Smallpox vaccination: comparison of self-reported and electronic vaccine records in the millennium cohort study. Hum Vaccin 2007, 3(6):245-51.

21. Uriell ZA, Burress L: Results of the 2005 Pregnancy and Parenthood Survey.Edited by: Navy Personnel Research S, and Technology. Millington: Bureau of Navy Personnel; 2007:

22. Landauer TK, Laham D, Rehder B, Schreiner ME: How well can passage meaning be derived without using word order? A comparison of Latent Semantic Analysis and humans.Edited by: Shafto MG, Langley P. Proceedings of the 19th annual meeting of the Cognitive Science Society Mahwah, NH: Erlbaum; 1997:412-417.

23. Landis JR, Koch GG: The measurement of observer agreement for categorical data. Biometrics 1977, 33:159-74.

24. Engel CC, Hyams KC, Scott K: Managing future Gulf War Syndromes: international lessons and new models of care. Philos Trans $R$ Soc Lond $B$ Biol Sci 2006, 361(1468):707-20.

25. Neville RG, Reed C, Boswell B, Sergeant P, Sullivan T, Sullivan FM: Early experience of the use of short message service (SMS) technology in routine clinical care. Inform Prim Care 2008, 16(3):203-11.

\section{Pre-publication history}

The pre-publication history for this paper can be accessed here: http://www.biomedcentral.com/1471-2288/11/136/prepub

\section{Submit your next manuscript to BioMed Central and take full advantage of:}

- Convenient online submission

- Thorough peer review

- No space constraints or color figure charges

- Immediate publication on acceptance

- Inclusion in PubMed, CAS, Scopus and Google Scholar

- Research which is freely available for redistribution

Submit your manuscript at www.biomedcentral.com/submit 